\title{
Integrated approach to structural diagnosis by non- destructive techniques: the case of the Temple of Minerva Medica
}

\author{
Ivan Roselli ${ }^{1}$, Angelo Tati ${ }^{1}$, Vincenzo Fioriti ${ }^{1}$, Irene Bellagamba ${ }^{1}$, Marialuisa Mongelli ${ }^{1}$, Roberto \\ Romano $^{1}$, Gerardo De Canio ${ }^{1}$, Mariarosaria Barbera ${ }^{2}$, Marina Magnani Cianetti ${ }^{2}$ \\ ${ }^{1}$ ENEA Casaccia Research Center, Rome, Italy \\ ${ }_{2}$ MIBACT Soprintendenza speciale per i Beni Archeologici di Roma, Rome, Italy
}

\begin{abstract}
In the present paper an integrated approach of a wide range of non-destructive tests (NDTs) was applied to study an archeological ruined building located in Rome, the so-called Temple of Minerva Medica. Applied NDTs focused on the monument properties and environmental conditions affecting its structural behavior (geometry, thermal and mechanical properties, microclimatic monitoring, ambient vibration response). Two surveys were performed in August and December 2016 combining 3D laser scanning, thermal infrared, air temperature and relative humidity acquisitions. In addition, high resolution digital images were acquired and processed by stereo-photogrammetry Structure from Motion ( $\mathrm{SfM}$ ) methodology, carried out for detailed reconstruction of the crack pattern of the monument. In order to obtain information on the integrity and consistency of the masonry, a sonic testing of each pillar was also performed. The integration of the above NDTs provided quite complete and comprehensive understanding of the structural behavior and state of the building, reducing the amount of invasive measurements further needed.
\end{abstract}

\section{Section: RESEARCH PAPER}

Keywords: non-destructive tests; integrated approach; archaeological building

Citation: Ivan Roselli, Angelo Tatì, Vincenzo Fioriti, Irene Bellagamba, Marialuisa Mongelli, Roberto Romano, Gerardo De Canio, Mariarosaria Barbera, Marina Magnani Cianetti, Integrated approach to structural diagnosis by non-destructive techniques: the case of the Temple of Minerva Medica, Acta IMEKO, vol. 7, no. 3, article 4, October 2018, identifier: IMEKO-ACTA-07 (2018)-03-04

Section Editor: Sabrina Grassini, Politecnico di Torino, Italy

Received February 25, 2018; In final form September 13, 2018; Published October 2018

Copyright: (C) 2018 IMEKO. This is an open-access article distributed under the terms of the Creative Commons Attribution 3.0 License, which permits unrestricted use, distribution, and reproduction in any medium, provided the original author and source are credited

Corresponding author: Ivan Roselli, ivan.roselli@enea.it

\section{INTRODUCTION}

In the context of restoration and conservation of archaeological heritage it is crucial to extract experimental data to characterise the physical and chemical properties of the materials that constitute historical objects. This allows more effective and optimized design of eventual interventions needed to repair or preserve these objects for future generations avoiding any risk of damage. Providing as much as possible complete and accurate characterisation of historical structures is particularly important in urban areas, which pose relevant problems in executing the restoration interventions. For example, this kind of situations are faced regularly in big cities that are rich in archaeological assets, subjected to potential degradation phenomena caused by urban pollution, traffic vibrations and excavation works that might threaten their structural stability. Such cases are very common in Italy, which presents the greatest concentration worldwide of historical constructions in urban areas, as documented by UNESCO World Heritage List, and in particular in the city Centre of Rome, where the needs of a modern European capital and its archaeological treasuries must coexist side by side. This is the case of the monument studied in the present paper, the socalled Temple of Minerva Medica, which is subjected to remarkable urban traffic vibration and pollution [1].

In order to give a contribution to the structural characterisation of the studied building without any risk of damaging the monument, a variety of non-destructive tests (NDTs) was carried out. The applied NDTs are the most advanced in their respective fields and are lately increasingly 


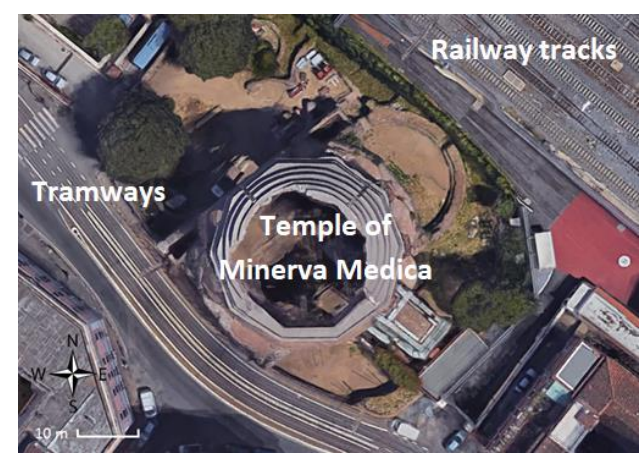

Figure 1. Aerial photo of the so-called Temple of Minerva Medica, Rome.

utilized. Nonetheless, they are mainly applied separately with no substantial integration. On the contrary, here NDTs were designed together and collected in an organic data repository.Also, taking into account a proper timing of acquisition of different kinds of data allowed to establish mutual relations and interdependences, which makes the whole experimental program systemic and integrated.

The executed measurements focused on surveying the geometry, the thermal properties and the integrity of the material constituting the monument. A particular focus was put on the physical properties that affect the dynamic characterization of the main hall, which is subjected to relevant vibration intensity induced by the surrounding tramways and railways traffic (Figure 1). A detailed 3D geometric reconstruction of the monument was achieved by integrating information from laser scanner surveys and from high resolution stereo-photogrammetry. Contemporarily, also thermographic imagery by infrared camera was collected, as well as data of microclimatic parameters, such as air temperature and relative humidity. Such measurements were important to evaluate the thermal behaviour of the masonry, which have a relevant influence also on the structural behaviour of the building, as well known [2]. In order to characterize the influence of microclimatic conditions on the dynamic response of the building, also ambient vibration measurements were carried out for modal identification of the structure. Sonic testing was performed to investigate the interior consistency of the pillars using the sonic transmission procedure [3].

\section{THE STUDIED MONUMENT}

Since the $16^{\text {th }}$ century, this ruined building was misinterpreted as a temple dedicated to Minerva Medica (Italian for "Minerva the Doctor"), as in this site an ancient statue with the likeness of this roman goddess was found. Nevertheless, according to more recent studies, archaeologists hypothesize it might have been part of the Horti Liciniani [4] or of another complex of Imperial Rome. It is located in the city-centre of Rome, on the Esquiline Hill, between via Labicana and Aurelian Walls.

The structure was initiated in early $4^{\text {th }}$ century A.D. as a majestic building. The main hall of the complex was probably a nymphaeum. It had a decagonal polylobate plan with a diameter of $25 \mathrm{~m}$ and an overall height of $32 \mathrm{~m}$. After several partial collapses during the past centuries, the size of the main hall is today almost unchanged, except for the height, which is currently reduced to only $24 \mathrm{~m}$ after a major dome collapse occurred in mid-19th century. The main hall presents two orders of arcades: on each of the ten sides (named as in Figure 2) a large arched niche is at ground level (first order arcade) over which there is a smaller arched window (second order arcade).

The structure was initially built in opus latericium, which was a common construction technique of that time, based on the use of Roman bricks and mortar. As the building started presenting structural problems, in the following centuries the construction was restored and reinforced. In this context, interventions in opus mixtum of tuff bricks and Roman bricks were carried out. In particular, most niches were closed and some walls with the function of buttresses were added on the southeast side of the monument, which testify that a certain structural weakness of this part already arose in ancient times. A further confirmation of such weakness in the south side is that the major historical damages, some of which were documented also by paintings in the $16^{\text {th }}$ through the $18^{\text {th }}$ century, were concentrated here, where recent investigations indicated that the foundations are less consistent [4]. Also, some major restoration interventions were carried out in the past. In 1846 first floor arcade of the southeast side was reconstructed, while the upper floor arcade of the southeast side was reconstructed in the years 2012-2013. The relevance of such a complex and long history of collapses and reconstructions lies in the fact that the monument now appears quite heterogeneous both in terms of construction materials and techniques, as well as irregular in shape.

\section{EXPERIMENTAL DATA}

The survey strategy comprised the design of data acquisition using a variety of in-situ measurement techniques capable of providing indications on the mechanical behaviour and the conservation state of the monument. Given the historical importance of the studied monument, only NDTs were considered. Data were recorded in a time span of one year, from July 2016 until July 2017, making possible to investigate the seasonal behaviour of the structure. In addition, also the eventuality of structural changes of the building due to the possible effects of the seismic sequence that hit Central Italy from August 2016 to February 2017 could be considered. In particular, in the present paper the results from the following measurements will be illustrated and integrated:

1) geometric survey by $3 \mathrm{D}$ laser scanner and stereophotogrammetry;

2) thermal imaging;

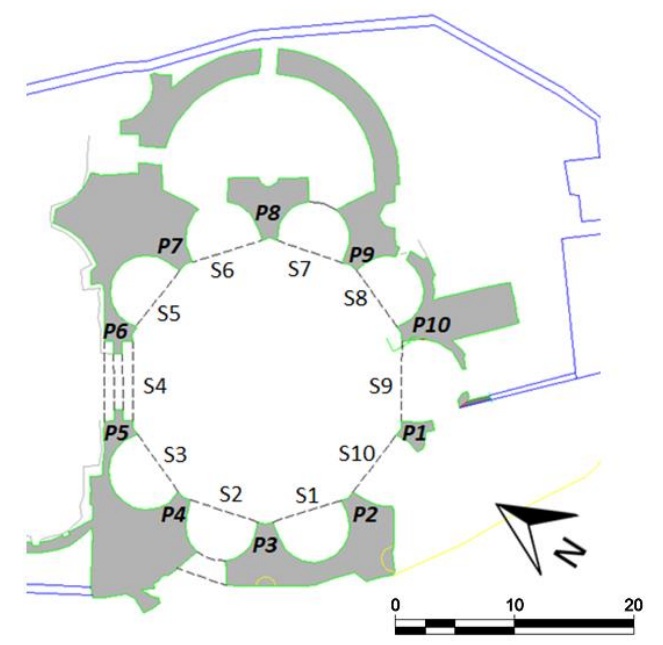

Figure 2. Decagonal plan of the main hall with sides (S1-S10) and pillars (P1P10) nomenclature. 
3) microclimatic characterization (air temperature and relative humidity);

4) ambient vibration measurements;

5) sonic testing of the pillars.

Microclimatic and ambient vibration data were acquired at the same time in order to characterize the environmental conditions under which the dynamic behaviour was identified.

\subsection{Geometric surveys}

\subsubsection{D laser scanner surveys}

The laser scanner measurements were acquired in summer of 2016 (August 5th) and in winter of 2016 (December 20th), when air temperatures were supposed to be the highest and the lowest of the year, respectively. Both acquisitions were carried out at 12 a.m., so that solar beams direction was essentially affected only by the season and not by the daytime, in order to analyse the seasonal effects neglecting the day/night cycle effects. The instrumentation used comprised a Riegl Z360 equipped with a Nikon D100 digital camera. The nominal angular resolution is $0.0025^{\circ}$ horizontal and $0.002^{\circ}$ vertical, while range accuracy was $+/-6 \mathrm{~mm}$. Through the use of retroreflecting targets, which were located at each pillar at the height $2.5 \mathrm{~m}$ from ground level, the two surveys could be compared by matching the targets positions as reference points. This $3 \mathrm{D}$ geometrical reconstruction by laser scanner was the base both for measurements of distances between walls at unreachable points and for the mathematical modelling for successive structural analyses. The plan of the main hall with sides (S1S10) and pillars (P1-P10) nomenclature is depicted in Figure 2. In particular, the ten diameters obtained as the distances between the internal walls of the opposite sides were calculated from both summer and winter surveys in order to assess the masonry expansion in each horizontal direction.

The overall expansion is the combination of the effects of masonry temperature and moisture deformations. In fact, construction materials are known to expand when heated and contract when cooled. In particular, ancient roman masonry, such as the one constituting the walls of the temple, have typical values of the thermal expansion coefficient that lie in the range of $3-8 \times 10^{-6}{ }^{\circ} \mathrm{C}[5]$. On the other hand, this historic masonry is also capable of absorbing water and, consequently, expand and contract again on drying. The thermal expansion is generally more intense than moisture deformations in case of high temperature excursion and dry climate. Nonetheless, as the December survey was carried out after a two-day rain of 12 $\mathrm{mm}$, the masonry was substantially wet to near saturation. On the contrary, the August survey was performed in a very hot and dry period. The found masonry expansion, expressed in terms of the percent variation (\%) between 3D laser scanning surveys of August and December 2016, is illustrated in Figure 3.

\subsubsection{Stereo-photogrammetric survey}

In addition to $3 \mathrm{D}$ laser scanning surveys, also a stereophotogrammetric survey was executed. About 500 digital images (10 Mpx each) were acquired by means of a Nikon D60 camera.

Subsequently, they were processed by Structure from Motion (SfM) methodology [6] using the Agisoft PhotoScan software via ENEAGRID, available on CRESCO (Computational Research Center for Complex Systems) HPC

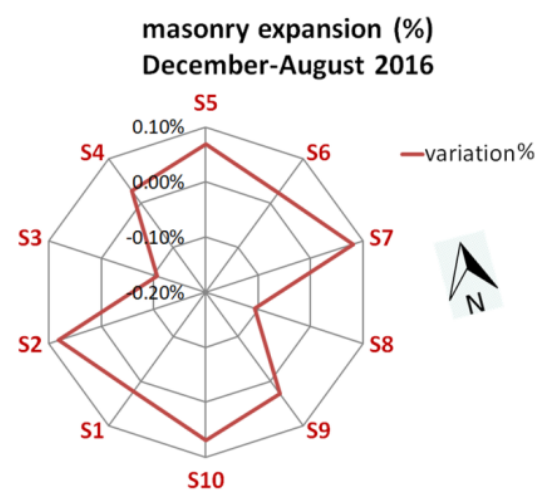

Figure 3. Variation (\%) of opposite sides distances between 3D laser scanning surveys of August and December 2016.

infrastructure [7]. A dense cloud of 30 million points was obtained and mesh returned more than 200,000 tria element.

Stereo-photogrammetry was used as a complementary tool to laser scanning, since it is able to provide more detailed documentation of the crack pattern [8], even if it provides a less accurate $3 \mathrm{D}$ geometry reconstruction.

Figure 4 shows a comparison between the raw digital image of side S4 and its reconstructed 3D rendering with texture after $\mathrm{SfM}$ processing. Background was eliminated so as to facilitate crack pattern recognition and analysis.

\subsection{Temperature and humidity measurements}

\subsubsection{Thermal imaging}

Thermographic data of the inner walls of the monument were acquired using a Flir T440 thermal infrared camera.

The building images were recorded from the centre of the main hall and were subdivided in 10 ground floor and 10 upper floor views, corresponding to the sides of the decagonal plan (Figure 5). The thermal images were captured at about 12 a.m. on the same two dates as the laser scanner surveys. A temperature diagram was obtained as a function of the walls solar exposure (ground and upper floor sides) for all acquired seasons, putting into evidence the thermal differences between walls. Minimum, maximum and average values of temperature excursion $\left({ }^{\circ} \mathrm{C}\right)$ between thermal imaging of August and December 2016 are depicted in Figure 6.
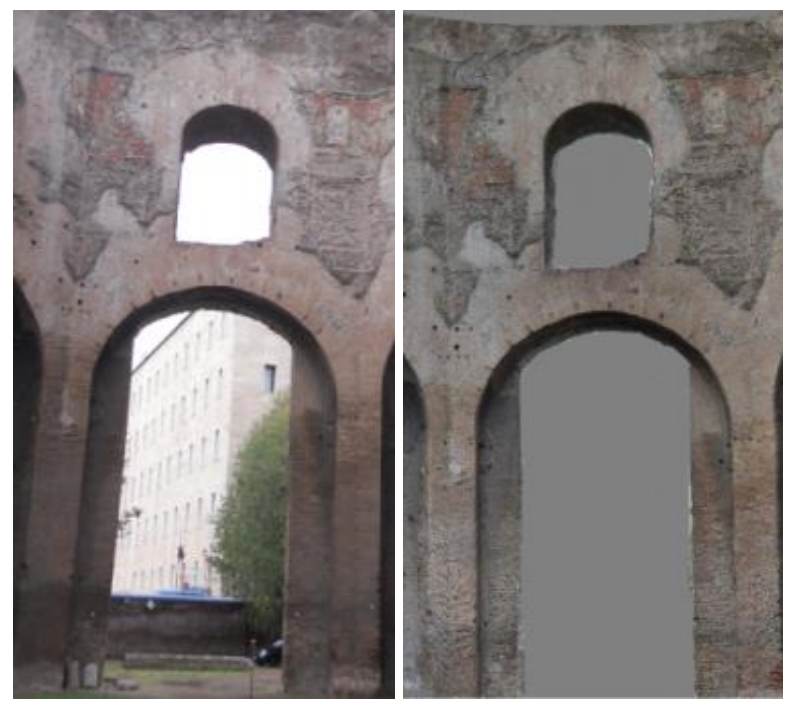

Figure 4. Digital photo (left) and related 3D texture (right) of northwest side S4 of the monument. 


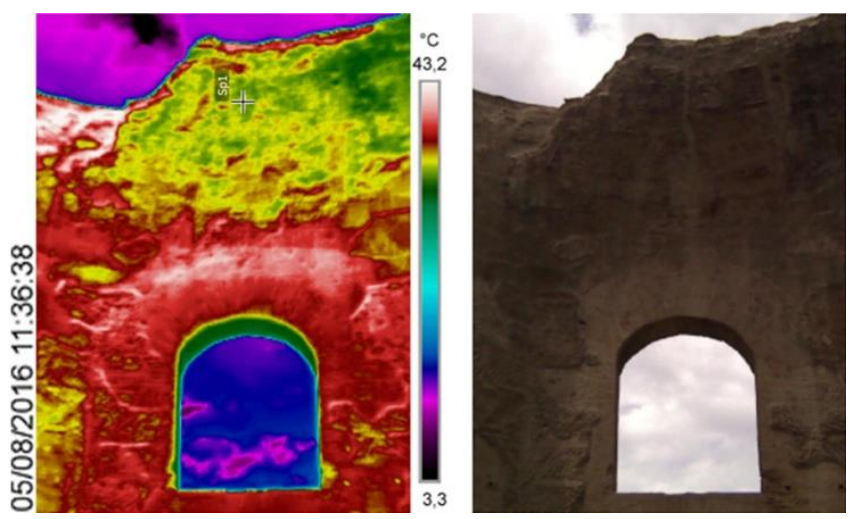

Figure 5. Thermal image of upper floor arcade on the northwest side (S3) of the monument (left) and corresponding photo (right).

Temperature excursions were more than $30^{\circ} \mathrm{C}$ between the maximum temperature values of the masonry recorded in August and in December surveys. The temperature of the walls was higher in the upper arcade and particularly in sides S2, S3 and S4 (north-western sides of the monument), where temperatures reached $40{ }^{\circ} \mathrm{C}$ in August.

This was a result of the direct solar beam exposure of their upper inner wall-faces due to the big hole left by the collapsed dome. Conversely, the walls on the eastern and southern sides (S6, S7, S8, S9 and S10) revealed maximum values of only 34$35{ }^{\circ} \mathrm{C}$. In the December survey the walls temperature resulted more uniform, increasing only slightly, from $8{ }^{\circ} \mathrm{C}$ at the bottom to $12{ }^{\circ} \mathrm{C}$ at the upper arcade. Solar beam direction was approximately the same, since the daytime of measurements was the same, but the effect of direct solar irradiation was very limited because it was a very cloudy day.

\subsubsection{Air temperature and relative humidity}

Two microclimatic monitoring stations were positioned on the west side (pillar P4 on side S2) and on the east side (pillar P8 on side S7). The microclimatic stations recorded air temperature and relative humidity by means of MSR145 mini data loggers during August and December surveys.

Consequently, the measured air temperatures could be correlated with the corresponding temperatures in the thermal images at the same positions. In Figure 7 the obtained correlation is illustrated. It shows that masonry temperatures resulted slightly lower than air temperatures in the December survey and, vice versa, slightly higher in August.

The excursion of the air temperature recorded by the microclimatic stations is indicated in Figure 6 where it can be

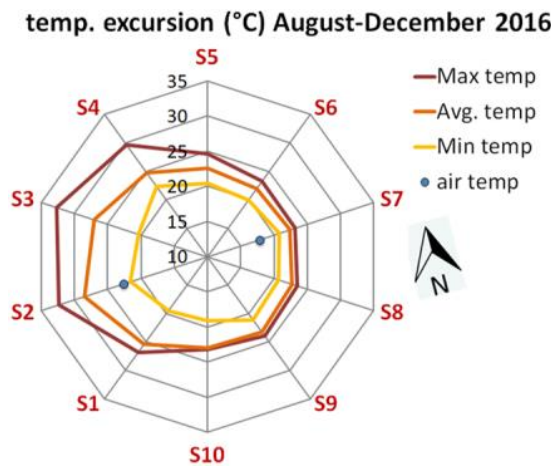

Figure 6. Minimum, maximum and average values of temperature excursion $\left({ }^{\circ} \mathrm{C}\right)$ between thermal imaging of August and December 2016 at 12 a.m. Air temperature excursion is also shown (blue dots).

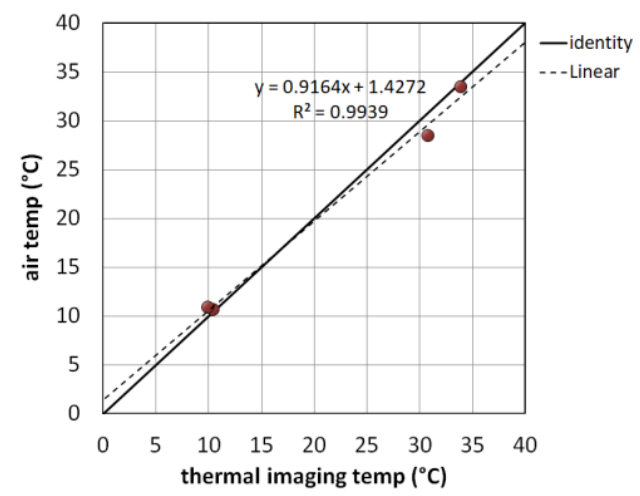

Figure 7. Correlation between air temperature and thermal imaging temperature at the same points.

compared with the temperature excursion by thermal imagery. Air temperature varies with less ample excursion than the walls temperature, as expected in consequence of typical masonry thermal behaviour.

As for the relative humidity, it resulted in the range 51-55\% in the August survey, while $71-72 \%$ in December.

To be noticed that higher values of humidity $(55 \%$ in August and $72 \%$ in December) were always measured at the station located in side S7, which indicates that on this side of the monument microclimatic conditions tend to induce more humid air.

\subsection{Ambient vibration measurements}

To assess the dynamic behaviour of the building, several measurement stations were located on the façade of the monument to acquire ambient vibration. They were made up of a digital recorder equipped with a triaxial velocimeter provided with a GPS antenna for time synchronization. The instruments were located as in Figure 8, simply laid on horizontal surfaces reachable by scaffoldings, at ground level, at windows and on the roof. Each measured position was acquired for at least 20 minutes at a sampling frequency of $200 \mathrm{~Hz}$, as in previous similar studies of historic masonry buildings [9].

The recorded vibration data were processed and analysed by several time- and frequency-domain modal analysis techniques [10-12] for mutual validation of results [13]. In fact, all modal analysis methods provided very similar values of the modal parameters, confirming the reliability of the results. Consequently, the average values calculated by the applied methods were considered in the following as the most reliable estimate of the natural frequencies of the monument. In the present study only the first four modes were considered, because higher modes are less relevant for the overall state of

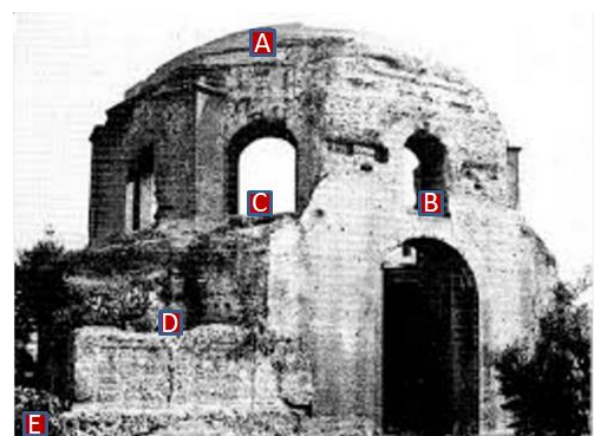

Figure 8. Ambient vibration measurement points on the main façade of the monument (view from North). 


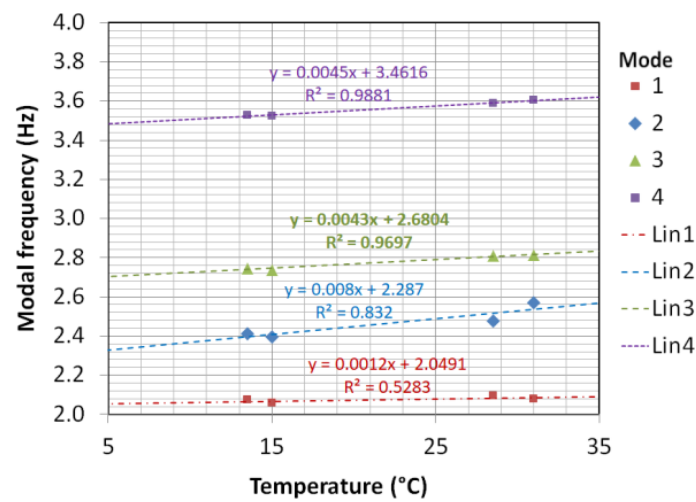

Figure 9. Influence of temperature on first four modal frequencies of the monument.

health of the structure, as they are representative of more local modes.

The initial outcomes showed that the considered modal frequencies resulted quite stable, though a slight variation was actually revealed. In fact, modal frequencies were a bit higher in spring and summer acquisitions. Consequently, the influence of the masonry temperature on the obtained frequencies was investigated. In particular, a remarkable correlation was found between the first four modal frequencies and the temperature, as showed in Figure 9. As quite common in historic buildings, the modal frequencies increased slightly with the temperature. However, recorded variations were limited in the range of $2-6 \%$, which is substantially coherent with a temperature excursion between about $10^{\circ} \mathrm{C}$ and $30^{\circ} \mathrm{C}$.

\subsection{Sonic testing of pillars}

One of the more critical uncertainties in the analysis of a historic masonry construction to assess its structural behaviour lies in the inner consistency or structure of walls, which may present voids or unknown materials. In these circumstances it is crucial to apply a NDT measurement technique able to provide indications on the inner structure of walls. The NDT methods based on the measurement of the velocity of sonic waves propagating through compact materials have such potentiality.

In February 2017 a series of sonic measurements was executed on all the pillars of the studied monument using the direct transmission procedure [14]. This technique implies the use of an instrumented hammer and a probe, both equipped with an accelerometer. Once the wanted path through the thickness of the wall is decided, the probe is laid on one end and the other end is hit by the hammer. The sonic wave propagates from one end to the other and the acquisition system records the acceleration time-histories of both sensors. After processing such time-histories the time of flight can be calculated and used as dividend of the path length to extract the sonic velocity.

The results of the direct sonic tests provide indications on the walls consistency, both in terms of masonry local mechanical properties (in particular, the Young's modulus can be estimated) and in terms of walls inner structure (voids, cavities, layers etc.).

In general, values lower than $800 \mathrm{~m} / \mathrm{s}$ indicate quite poor mechanical properties, while values in the range $1500-2500 \mathrm{~m} / \mathrm{s}$ are typical of good quality historic masonry. Inner voids and cracks induce sonic velocity decrease in comparison to surrounding masonry. Since this technique is especially effective for investigating heterogeneities in the construction materials,

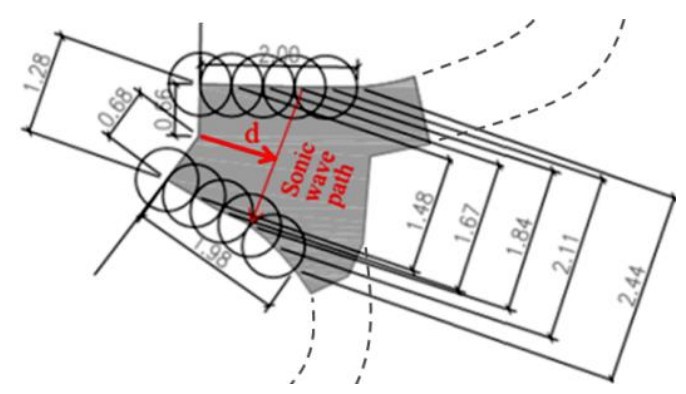

Figure 10. Pillar P1 plan view with configurations of sonic wave velocity measurement (unit is $\mathrm{m}$ ).

such as historic masonry, it allows the identification of layering of the sections, the presence of voids, cavities and anomalies in material density.

In particular, it was applied to the base of each pillar in order to verify the state of compacity of the masonry and to estimate its compression strength. The used equipment comprised an instrumented hammer with a PCB ICP accelerometer, as well as the probe, both cabled to the acquisition unit. Data were acquired with a sampling frequency of $500 \mathrm{kHz}$. The applied measurement procedure was strictly in accordance to the UNI 10627-1997 standard [15].

The acquisition configurations were as depicted in Figure 10 for pillar P1. It shows the sonic path length and the meaning of $\mathrm{d}$, which is the distance from internal pillar face to the path line. Because of the particular geometry of pillars, the acquisition with the utilized instrumentation was possible only on the two radial faces. In particular, as the points on the outer sides of pillars could not be acquired, a rectangular grid could not be performed and a representative 2D tomography could not be obtained. Consequently, only 1D sonic wave velocity distribution could be detected (in radial direction), which however provided interesting indications.

In particular, in Figure 11 a graph of the sonic test velocity recorded at each pillar versus $d$ is depicted. Initial values $(d=0)$ tend to decrease at higher values of $d$, indicating poorer material properties of the core (opus caementicium) with respect to the wall-face brickwork layers (opus latericium or mixtum). The low initial value of pillar P4 is due to a crack in the wall-face layer. The lowest values were measured in pillars P9 and P10 at $\mathrm{d}$ in the range $80-120 \mathrm{~cm}$. For $d>120 \mathrm{~cm}$ the lowest values were obtained for pillars P1 and P2.

The diagram in Figure 12 illustrates the average values of sonic velocity recorded at each pillar. It suggests that pillars from P3 to P8 (clockwise from southwest to northeast) are characterized by higher average consistency than the remaining

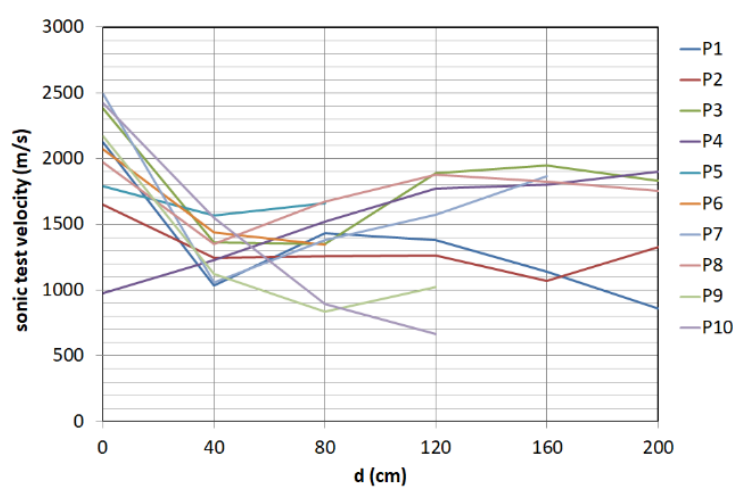

Figure 11. Sonic test velocity recorded at each pillar (P1 to P10) in function of the distance from internal face (d) defined as in Figure 10. 


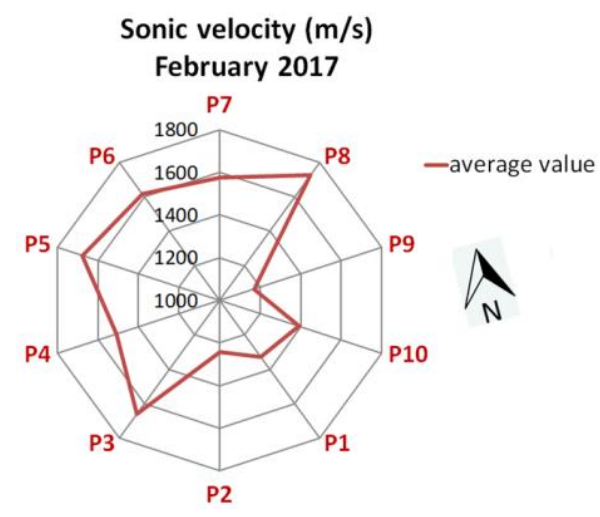

Figure 12. Average values of sonic test velocity recorded at each pillar

pillars in east and south sides.

It is worth noting that pillar P1 was entirely reconstructed in 1846, when a major restoration intervention was carried out to rebuild the portion of the ground floor arcade that goes from P10 to P2 clockwise. On the other hand, P9 and P10 values are very low, but they do not apparently show any external defect, as confirmed by their good values in the first $40 \mathrm{~cm}$ of $\mathrm{d}$, which may indicate that these pillars have a different internal structure.

It is also worth noting that the sonic test results can be considered as local measurements of the material stiffness between the measurement points (i.e. they are essentially related to the average Young's modulus of the material within the sonic wave path). Even if it is a measurement of substantially local nature, it gives the structural engineers indications on the building process of the entire structure. Especially, considering that the material stiffness practically is the main factor that determines the dynamic behaviour of the structure, once that mass and geometry remain unchanged. Consequently, sonic velocity measurements are very relevant to understand the structural behaviour in relation with the modal frequencies identified through the ambient vibration acquisitions. All above information is essential to create a representative numerical model of the building that could be used for further structural analyses and simulations.

\section{CONCLUSIONS}

The present paper illustrates how the integration of different kinds of measurements extracted from the application of a variety of NDT techniques provided a significant contribution to the study of the so-called Temple of Minerva Medica. The several investigated physical properties about the monument and its local environmental conditions were integrated in an effective database for a comprehensive understanding of the overall structural behaviour.

In particular, the influence of the geometry and of the environmental conditions (especially, in terms of solar exposure) on the thermal behaviour of the structure was highlighted. The thermal conditions are among the main factors affecting the dynamic behaviour of historic masonry structures, which was evidenced by the high correlations found between the monument's modal frequencies with the temperature. The integration of thermal imagery with microclimatic stations providing the air temperature and the relative humidity, taking into account also the weather records (e.g. rainfall records) for the acquisition dates, allowed a more comprehensive understanding of the actual environmental conditions and their effect on the structural properties of the studied structure.
Moreover, the mechanical properties of the masonry, investigated by sonic tests and the surveyed crack pattern by stereo-photogrammetric tools, will be fundamental for the production of representative numerical models, e.g. finite element models (FEMs), to be used for more reliable subsequent structural analyses.

The presented study confirms that an integrated multisensor and multi-disciplinary approach can be successfully applied to the study of a heterogeneous and complex object, such a historic structure that was subjected to a variety of major changes and interventions during its age-old life.

\section{ACKNOWLEDGEMENT}

The present work was conducted within the framework of the CO.B.RA. project, which focused on the development of advanced technologies and methods for the conservation of cultural heritage assets, funded by Lazio Region, Italy.

\section{REFERENCES}

[1] I. Roselli, V. Fioriti, I. Bellagamba, M. Mongelli, A. Tatì, M. Barbera, M. Magnani Cianetti, G. De Canio, "Urban transport vibrations and cultural heritage sites in Rome: the cases of the temple of Minerva Medica and of the Catacomb of Priscilla", WIT Transactions on Ecology and the Environment 223(2017) pp. 335-343, DOI: 10.2495/SC170291.

[2] H. Nandan, M.P. Singh, "Effects of thermal environment on structural frequencies: Part I - A simulation study", Eng. Struct. 81(2014) pp. 480-490, DOI: 10.1016/j.engstruct.2014.06.046.

[3] M. R. Polimeno, I. Roselli, V. A. M. Luprano, M. Mongelli, A. Tatì, G. De Canio, "A non-destructive testing methodology for damage assessment of reinforced concrete buildings after seismic events", Eng. Struct. 163(2018) pp. 122-136, DOI: 10.1016/j.engstruct.2018.02.053.

[4] M. Barbera, M. Magnani Cianetti, S. Barrano, "Da Massenzio a Costantino: le indagini in corso nel c. d. tempio di Minerva Medica”, Proc. of the International Conference of CISEM - La villa restaurata e i nuovi studi sull'edilizia residenziale tardoantica (in Italian), November 7-10, 2012, Piazza Armerina, Italy, pp. 1613-1624.

[5] K. Van Balen, I. Papayianni, R. Van Hees, L. Binda, A. Waldum, "Introduction to requirements for and functions and properties of repair mortars", Materials and Structures 38 (2005) pp. 781 785, DOI: $10.1007 / \mathrm{BF} 02479291$.

[6] G. Verhoeven, "Taking computer vision aloft_-archaeological threedimensional reconstructions from aerial photographs with Photoscan", Archaeol. Prospection 18(2011) pp. 67-73, DOI: 10.1002/arp.399.

[7] G. Ponti et al., "The role of medium size facilities in the HPC ecosystem: the case of the new CRESCO4 cluster integrated in the ENEAGRID infrastructure", Proc. of the International Conference on High Performance Computing and Simulation (HPCS), July 21-25, 2014, Bologna, Italy, DOI: 10.1109/HPCSim.2014.6903807.

[8] M. Mongelli, G. De Canio, I. Roselli, M. Malena, A. Nacuzi, G. De Felice, "3D photogrammetric reconstruction by drone scanning for FE analysis and crack pattern mapping of the bridge of the towers, Spoleto", Key Engineering Materials 747(2017) pp. 423-430, DOI: 10.4028/www.scientific.net/KEM.747.423.

[9] I. Roselli, M. Malena, M. Mongelli, N. Cavalagli, M. Gioffrè, G. De Canio, G. De Felice, "Health assessment and ambient vibration testing of the Ponte delle Torri of Spoleto during the 2016-17 Central Italy seismic sequence", Int. J. Civil Structural Health Monitoring 8-2(2018), DOI: 10.1007/s13349-018-0268-5.

[10] C. W. De Silva, Vibration and Shock Handbook, CRC Press, 2005, eBook ISBN: 9781420039894. 
[11] G. De Canio, M. Mongelli, I. Roselli, A. Tatì, D. Addessi, M. Nocera, D. Liberatore, "Numerical and operational modal analyses of the Ponte delle Torri, Spoleto, Italy", Proc. of the 10th International Conference on Structural Analysis of Historical Constructions (SAHC), 2016, pp. 752-758, eBook ISBN: 978-1-315-61699-5.

[12] M. R. Gallipoli, M. Mucciarelli, M. Vona, "Empirical estimate of fundamental frequencies and damping for Italian buildings", Earthquake Engineering \& Structural Dynamics 38-8(2009) pp. 973-988, DOI: $10.1002 /$ eqe.878.

[13] I. Roselli, V. Fioriti, M. Mongelli, I. Bellagamba, G. De Canio, "Mutual validation between different modal analysis techniques for dynamic identification of the so-called Temple of Minerva Medica, Rome", IOP Conf. Series: Materials Science and Engineering $\quad 364-1(2018), \quad$ DOI: $\quad 10.1088 / 1757-$ 899X/364/1/012004.

[14] S. Hum-Hartley, Nondestructive Testing for Heritage Structures, Bulletin of the Association for Preservation Technology 103(1978) pp. 4-20, DOI: $10.2307 / 1493664$.

[15] UNI 10627:1997. Sistemi di tomografia computerizzata per indagini strutturali (Italian Standard), http://hdl.handle.net/11573/65727. 